\title{
Awareness of adverse drug reactions in third M.B.B.S students practicing self-medication
}

\author{
Shreyas R. Burute ${ }^{1 *}$, Ramchandra B. Burute ${ }^{2}$, Mangala B. Murthy ${ }^{1}$, Vitthal B. Karande ${ }^{1}$, \\ Shraddha M. Pore ${ }^{1}$, Sunita J. Ramanand ${ }^{1}$
}

${ }^{1}$ Department of Pharmacology, Government Medical College, Miraj. Maharashtra,India,

${ }^{2}$ Department of Anesthesiology, Institute of Medical Sciences and Research, Mayani, Maharashtra, India

Received: 14 December 2015

Accepted: 7 January 2016

*Correspondence to:

Dr. Shreyas R. Burute,

Email: shreyas.burute@gmail.com

Copyright: () the author(s), publisher and licensee Medip Academy. This is an open-access article distributed under the terms of the Creative Commons Attribution Non-Commercial License, which permits unrestricted non-commercial use, distribution, and reproduction in any medium, provided the original work is properly cited.

\begin{abstract}
Background: Students self-medicate but the extent of their knowledge regarding potential adverse drug reactions (ADRs) to drugs consumed by them is not known. This has many implications. This study has attempted to evaluate this knowledge in third MBBS students practicing self-medication.

Methods: In this cross-sectional study, a self-designed, pretested questionnaire was presented to third MBBS students in a teaching hospital. Information sought:-Demographic data, self-medication drugs used within last one month, indication, duration, awareness and expected ADRs for the drugs consumed. Results were calculated as percentages.

Results: 79 out of 87 third MBBS students present on the day of study were presented with questionnaire all attempted it; giving a response rate of $100 \%$. Within the last one month $31(39.24 \%)$ had self-medicated. There was no significant difference in self-medication between male and female students. Medication was used for adequate duration (93.87\%) and for apparently correct indications $(81.6 \%)$ by most students. Main group of drugs consumed were NSAIDs including antipyretics $(42.59 \%)$, antibiotics $(18.53 \%)$ and antihistaminics $(16.66 \%)$. Fourteen $(45.16 \%)$ students said they were aware of potential ADRs to the consumed drugs and 13 (43.93\%) listed expected ADRs correctly .Although a wide range of drugs were consumed, the number of ADRs mentioned were few and its spectrum limited. 11 (35.48\%) students mentioned only one ADR. No student mentioned more than two ADRs. Dyspepsia (56.25\%) was most common ADR stated.

Conclusions: Considering the wide range of drugs consumed, the numbers of ADRs mentioned were few and their spectrum limited indicating scope for improvement.
\end{abstract}

Keywords: Self-medication, Expected adverse drug reactions, Adverse drug reaction awareness

\section{INTRODUCTION}

Studies have shown that taking medication by self for illness is common practice in people, ${ }^{1-3}$ especially when there is previous exposure to the illness or when it is presumed to be minor illness. ${ }^{1,4}$ Responsible selfmedication dictates the use of safe and effective nonprescription drugs available over the counter (OTC) to treat one's own illness. It also requires the consumer to be informed about proper use, potential side effects, possible interactions and the knowledge of when to seek a doctor's consultation. ${ }^{5}$ When medical students selfmedicate they are expected to do so more responsibly since they are expected to be aware of all aspects of drug use. In fact medical students themselves felt that medical knowledge would make them more careful about selfmedication. ${ }^{6}$

It is now well established that lay people as well as medical students self-medicate not only with OTC drugs but also with prescription drugs, which are strictly to be taken on doctor's prescription. ${ }^{7,8}$ Thus exposing themselves to the risk of adverse drug reactions (ADRs). A study cites that $1.72 \%$ out of $9.78 \%$ of ADRs related admissions to emergency wards of 11 French academic hospitals were due to self-medication. ${ }^{9}$ These ADRs were caused due to both prescription and non-prescription drugs. 
Medical students, in many studies have identified adverse drug reactions (ADRs) as a concern while selfmedicating. ${ }^{6,10}$ In another study evaluating the content of drugs stored at home, medical students have identified if these drugs had the potential to cause toxicity. ${ }^{11}$ Even then this does not necessarily give a complete picture of whether the students were actually aware of the potential ADRs to the drugs most commonly consumed by them for the purpose of self-medication. Understanding the level of awareness in medical students is important because unlike nonmedical students, the implications are not limited to merely increased risk to the students themselves, but possibility of self-medication related behaviour being carried into their future is real. ${ }^{12}$ As such lack of awareness to ADRs may adversely affect the quality of future prescribing, may interfere with quick diagnosis and treatment of ADRs thus affecting patient care and compromise pharmacovigilance activities. ${ }^{13} \mathrm{On}$ the other hand studying the level of awareness amongst students may help us, as teachers, to gauge the effectiveness of our present teaching pattern and accordingly modify our teaching methods.

We have not come across any study, highlighting to what extent students are aware and knowledgeable of ADRs to the drugs they have self-medicated with. We thus decided to evaluate the awareness and correctness of potential ADRs mentioned by third MBBS students practicing selfmedication.

\section{METHODS}

This cross-sectional study was carried out in a tertiary teaching hospital and was approved by Ethics committee. A self-designed, pretested questionnaire containing both close and open ended items was presented to third MBBS students after explaining the nature and conduct of study and obtaining their written written consent. We chose third MBBS students because unlike first MBBS students who are not exposed to pharmacology course and second MBBS students who are still in the midst of the course, third MBBS students are expected to be aware of all aspects of drug use covered during second year Pharmacology course.

Information regarding demographic data, drugs used for self-medication (operationally defined for this study as taking medication without doctor's prescription) within last one month, indication, duration, schedule of drug, awareness of ADRs and list of expected ADRs for the drugs consumed by self was sought. List of expected ADRs was further analysed for correctness, number of ADRs mentioned. Frequency of stated ADRs to determine the commonest one was calculated.

Results were calculated as percentages. Fisher's exact test was used to test statistical significance between genders for self-medication, $\mathrm{p}$-value of $\mathrm{p}<0.05$ was considered significant.

\section{RESULTS}

All 79 out of 87 third MBBS students present on the day of study were presented with questionnaire after written consent and all attempted it; giving a response rate of $100 \%$. Within the last one month 50 students had taken medication. Out of these $31(39.24 \%)$ had consumed medicine by self. Stastically no significant difference was observed in self-medication between male and female students (Figure 1).

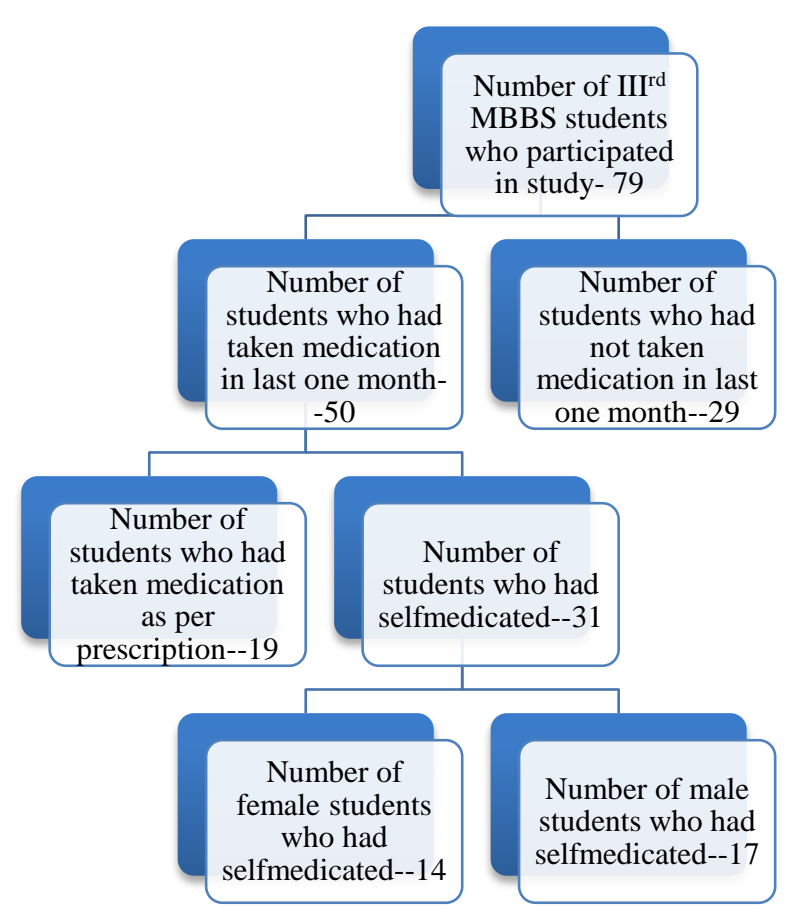

Figure 1: The breakup of students taking medication within last one month.

Medication was used for apparently correct indications $(81.6 \%)$ by most students. The most common indication for self-medicating was pain (including headache, body ache) and/or fever $(35.71 \%)$ followed by flu/cold (17.80\%), apparent infections (14.28\%) and gastrointestinal complaints (10.70\%) (Figure 2). One student used ciprofloxacin for upper respiratory tract infection. Medicines were also used for apparently adequate duration $(93.87 \%$ ) except that erythromycin was used for two days and doxycycline for one day respectively by two students.

Nonsteroidal anti-inflammatory drugs (42.59\%) including paracetamol $(27.77 \%)$ and its fixed dose combinations (FDCs $11.11 \%$ ) with other analgesics/caffeine/diclofenac were most commonly consumed (Table1).This correlates well with the most common indication i.e pain/fever. Other common drug groups were antimicrobials (18.53\%) and $\mathrm{H}_{1}$ antihistaminic (16.66\%).Vitamins and nutritional supplements $(9.25 \%)$, drugs for gastritis (7.4\%) and antidiarrhoeal drugs $(3.7 \%)$ were also used. On an average each student consumed $1.74 \%$ drugs. A total of $24.07 \%$ FDCs were consumed by students (Table 
1). Twenty two different types of drugs were consumed and sixteen drugs out of these were schedule $\mathrm{H}$ drugs. None of the students mentioned being on medication for any chronic condition.

Twenty five out of the thirty one students took the drug themselves without consulting pharmacist, parents or friends (Table 2). Three students had consulted a physician initially, but modified the drug course later. As seen in Table 3 Majority $25(80.64 \%)$ considered the illness mild enough not to consult a doctor, $21(67.74 \%)$ believed they had previous experience with the illness while $13(41.93 \%)$ used the medication because they already had it with them.

Table 1: Drug groups and the frequency of consumption of different drugs by students.

\begin{tabular}{|c|c|c|c|c|}
\hline Sr.no. & Drug group & Drug name & $\begin{array}{l}\text { Consumed } \\
\text { by } \\
\text { number of } \\
\text { students } \\
(\mathrm{n}=31)\end{array}$ & $\begin{array}{l}\text { Frequency } \\
\text { of } \\
\text { consumption }\end{array}$ \\
\hline \multirow{5}{*}{1.} & \multirow{5}{*}{$\begin{array}{l}\text { Nonsteroidal anti- } \\
\text { inflammatory drugs }\end{array}$} & Paracetamol & 15 & $27.77 \%$ \\
\hline & & $\begin{array}{l}\text { Fixed dose combinations of paracetamol with } \\
\text { Ibuprofen/diclofenac/caffeine }\end{array}$ & 6 & $11.11 \%$ \\
\hline & & Ibuprofen & 1 & $1.85 \%$ \\
\hline & & Nimesulide & 1 & $1.85 \%$ \\
\hline & & Total & 23 & $42.59 \%$ \\
\hline \multirow{6}{*}{2.} & \multirow{6}{*}{ Antimicrobials } & $\begin{array}{l}\text { Macrolides (erythromycin,azitromycin, } \\
\text { roxithromycin) }\end{array}$ & 5 & $9.25 \%$ \\
\hline & & Cephalosporins & 2 & $3.70 \%$ \\
\hline & & Ciprofloxacin & 1 & $1.85 \%$ \\
\hline & & Doxycycline & 1 & $1.85 \%$ \\
\hline & & Albendazole & 1 & $1.85 \%$ \\
\hline & & Total & 10 & $18.51 \%$ \\
\hline \multirow{5}{*}{3.} & \multirow{5}{*}{ Antihistaminics } & Levocetrizine & 5 & $9.25 \%$ \\
\hline & & Cetrizine & 2 & $3.70 \%$ \\
\hline & & Fexofenadine & 1 & $1.85 \%$ \\
\hline & & Chlorpheniramine & 1 & $1.85 \%$ \\
\hline & & Total & 9 & $16.66 \%$ \\
\hline \multirow{4}{*}{4.} & \multirow{4}{*}{$\begin{array}{l}\text { Drugs used for } \\
\text { gastrointestinal } \\
\text { indications }\end{array}$} & Ranitidine & 3 & $5.55 \%$ \\
\hline & & Antacid & 1 & $1.85 \%$ \\
\hline & & Diphenoxylate +atropine & 2 & $3.70 \%$ \\
\hline & & Total & 6 & $11.11 \%$ \\
\hline 5. & $\begin{array}{l}\text { Vitamins/nutritional } \\
\text { supplements }\end{array}$ & Multivitamins & 5 & $9.25 \%$ \\
\hline \multirow[t]{2}{*}{6.} & Bronchodilator & Salbutamol & 1 & $1.85 \%$ \\
\hline & & Grand total & $54 *$ & $99.97 \%$ \\
\hline
\end{tabular}

*Students consumed more than one drug hence total drug consumption is more than 31

Table 2: Sources with whom the students consulted prior to self-medicating.

\begin{tabular}{|lll|}
\hline Sr.no. & Source of information/drug & $\begin{array}{l}\text { Number of students } \mathbf{n}(\boldsymbol{\%}) \\
(\mathbf{n = 3 1})\end{array}$ \\
\hline 1. & Pharmacist & $0(0 \%)$ \\
\hline 2. & Parents & $5(16.12 \%)$ \\
\hline 3. & Friend/s & $1(3.22 \%)$ \\
\hline 4. & I took it myself & $25(80.64 \%)$ \\
\hline & Total & 31 \\
\hline
\end{tabular}

Fourteen $(45.16 \%)$ out of thirty one self-medicating students stated they were aware of expected ADRs to the drugs they had consumed. $13(43.93 \%, 13 / 31)$ out of 14 students listed expected ADRs correctly. Of these eleven students stated one ADR, two stated two ADRs, while one stated an unlikely ADR. Notably none mentioned more than two ADRs. Seventeen $(54.83 \%)$ were not aware of ADRs or did not attempt the item (Figure 3). 
Nine of the fourteen students correctly stated dyspepsia (includes peptic ulcers, gastric irritation etc.) as an expected ADR and it was the most common ADR mentioned by students. Sedation, drowsiness, palpitation and tremors were other expected ADRs stated by a student each (Figure 4). Hepatotoxicity in overdose for paracetamol was also stated by two students.

Table 3: Reasons behind self-medication.

\begin{tabular}{|lll|}
\hline Sr. no. & Reasons & Number of students $\mathbf{n}(\%) * \mathbf{n}=\mathbf{3 1}$ \\
\hline 1. & The illness was too mild so did not feel the need to see a doctor. & $25(80.64 \%)$ \\
\hline 2. & Had previous experience with similar illness & $21(67.74 \%)$ \\
\hline 3. & Availability of doctor not easy/time consuming & $3(9.67 \%)$ \\
\hline 4. & I already had the medicine with me & $13(41.93 \%)$ \\
\hline & Total & 62 \\
\hline
\end{tabular}

*Since students marked more than one option, the total is more than $31(100 \%)$

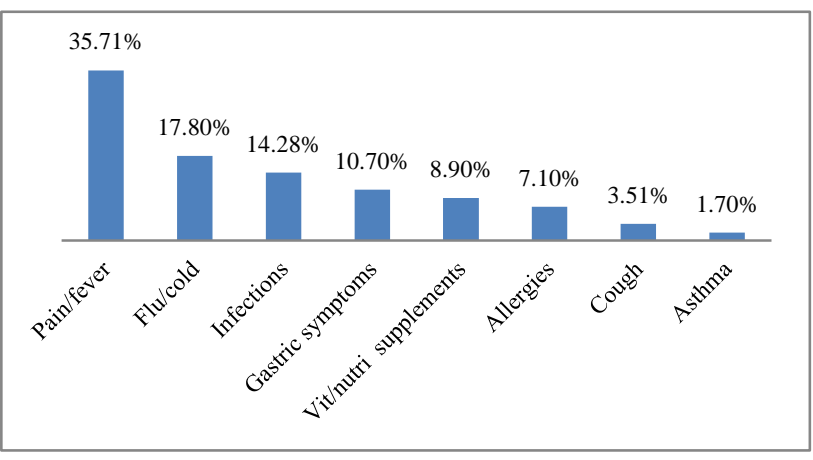

Figure 2: Indications for self-medication as mentioned by students.

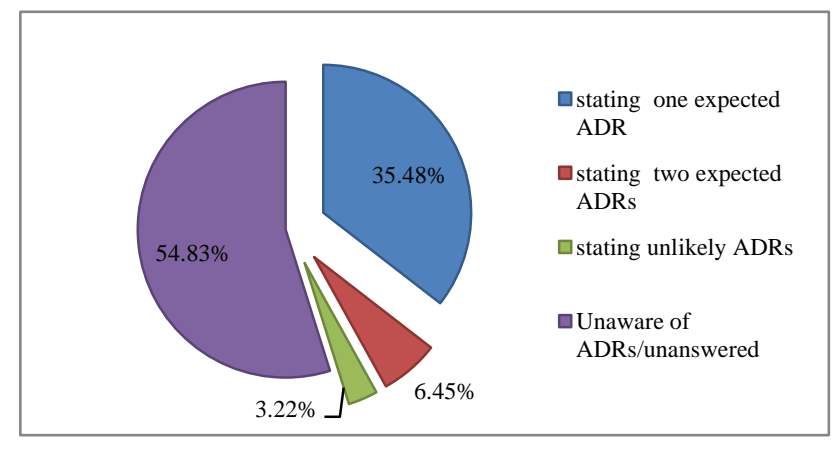

Figure 3: Student's awareness of expected ADRs to drugs consumed.

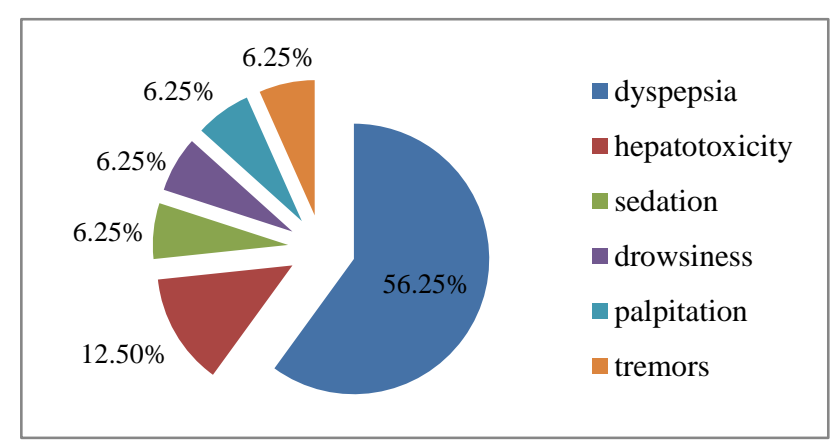

Figure 4: Frequency of ADRs stated correctly by students.

\section{DISCUSSION}

It is now well understood that medical students selfmedicate. ${ }^{8,14-16}$ In the present study $39.24 \%$ third MBBS students self-medicated. This is less than other Indian studies which reported a prevalence of $74.71 \%{ }^{10}$ and $79.31 \% .^{15}$ As such a varying prevalence has been observed in various places. ${ }^{1,6,10,15}$ Variations in gender as a liability for increased tendency towards self-medication have been observed. Some studies identify increased tendency in males ${ }^{14}$ some in females ${ }^{16,17}$ while others show no difference. ${ }^{1}$ The present study does not show any significant difference with regards the prevalence of self-medication in male and female students.

The main indications in the present study were pain/fever, cold/flu, infections and gastric symptoms (Figure 2). These are similar to observations by Sontakke SD et al. ${ }^{10}$ Overall a wide range of drugs were consumed (Table 1) for apparently correct indications (81.6\%) and duration (93.87\%). The most common drug used was paracetamol and its FDCs. Other studies have also reported predominant use of paracetamol. ${ }^{1,6}$ This was followed by antimicrobials and $\mathrm{H}_{1}$ antihistaminergic drugs (Table 1) in present study. The use of antimicrobials $(18.53 \%)$ though less than that reported by Bala R et al (74\%) in Punjab; ${ }^{18}$ is of particular concern not only because of the risk of hypersensitivity reactions and development of antimicrobial resistance, but it underlines the casual attitude students have towards preventing development of antimicrobial resistance. Notably like other Indian studies ${ }^{10,15,17}$ none of the students mentioned using oral contraceptive pills as compared to studies outside India ${ }^{1,14}$ thus probably reflecting a sociocultural influence. Out of the 22 drugs consumed, a whopping 16 were schedule $\mathrm{H}$ drugs; meant to be taken by prescription only. Results of other studies also cite self-medication with prescription drugs, thus underlining the universality of the problem. . $^{1,6,1,10,11,17-20}$ Quite a few students consumed FDCs (24.07\%), especially for pain/fever. This may point towards a trend of using irrational combinations early in their medical career. Results of other studies show that use of FDCs is 
prevalent in general population ${ }^{21,22}$ and nonmedical students. ${ }^{3}$ Thus this trend may possibly be rooted in selfmedication practices at their homes.

Majority of the students took the drug themselves without consulting pharmacist, parents or friends (Table 2). This is in accordance with other studies on medical students ${ }^{16,17}$ but in contrast to nonmedical self-medicating population, 4,7,19,21 where family/friends and/or pharmacist were consulted. As seen in Table 3, majority $25(80.64 \%)$ considered the illness mild enough not to consult a doctor or believed they had previous experience with the illness. This again is in accordance with other studies ${ }^{15-17,23,24}$ but in contrast to a study in rural population of Maharashtra, wherein the major reason was economic and non-availability of health care facilities. ${ }^{25}$ This may thus indicate a similar behavioural aspect amongst medical students. In fact $62.7 \%$ of medical students in Nepal strongly believed that self-medication without proper knowledge of drugs and disease would not be harmful. ${ }^{23}$ Another similar aspect with this study was that in the present study too, difficulty /lack of time in access to a doctor was not a major influencing factor for self-medication. ${ }^{23}$ The possible reason as discussed by Roberts LW et al could be the discomfort felt by students in dual role of student patient. ${ }^{26}$

Student's awareness [14 (45.16\%) ] about ADRs to drugs they consumed was less as compared to a study by Sontakke SD et al $(76.96 \%)$ and Badiger S et al $(67.4 \%){ }^{10,24}$ The possible reason could be that in the first part of the item, the students were asked if they were aware of ADRs to the drugs they had consumed. If they claimed awareness then in the second part we requested them to list the potential ADRs. Hence only those aware must have attempted. The fact that $13(92.85 \%)$ out of the 14 students who claimed to be aware of ADRs, listed potential ADRs correctly seems to corroborate this.

The numbers of ADRs mentioned were few and limited mostly to dyspepsia (Figure 4) even though a wide variety of drugs were consumed (Table 1). In Belgrade out of the $1 \%$ medical students who reported an adverse reaction, $0.6 \%$ reported allergic reactions while the rest did not specify what reaction they had. ${ }^{16}$ In present study none mentioned more than two ADRs. $54.83 \%$ were not aware/did not answer this question leading us to believe that students probably forgot ADRs since they passed Pharmacology. If these findings are viewed taking into consideration that 1) Most students consumed more than one drug/FDC.2) Sixteen drugs out of twenty two consumed were scheduled drugs and require prescription 3) Majority self-medicated without even an informal consultation and 4) believed their illness to be mild (which could be misleading); the readers can get a glimpse of the potential risk the students expose themselves to. Not surprisingly students themselves acknowledge the risk involved. ${ }^{6,10,23}$ Adverse drug reactions to self-medication have been assessed earlier in general population as well as in medical students. In these studies it was found to be as high as $43 \%^{21}$ and $5.4 \%{ }^{24}$ respectively.

Since it is now evident that self-medication is prevalent everywhere, our focus should primarily be on making it safer by 1) Educating the users and 2) Restricting easy availability of prescription drugs. 3) Ingraining into student's mind that the risk of ADRs to any drug is real. The last could possibly be ensured by 1) Effective use of audio-visual aids (photographs, video clips, actual slides of abnormal blood counts/morphology, presenting cases of drug induced diseases during seminars or preferably at bedside). 2) Actively enlisting the students in pharmacovigilance related activities like identifying, collecting and/or filling ADR reporting forms, assessing causality under supervision.

Like most questionnaire based studies this study is limited in its scope due to inherent limitations of selfreporting like recall bias. The authors have tried to minimize this by asking for self-medication history only within the last one month. Further since the questionnaire was administered in the class room, peer influence cannot be ruled out. The present study did intend to evaluate the awareness in students about potential drug interactions between the drugs consumed by self and those prescribed for any chronic condition they had. None of the 31 students reported being treated for any chronic condition, so we could not analyse this further.

\section{CONCLUSION}

Awareness of ADRs is low considering the wide range of drugs consumed. The numbers of ADRs mentioned were few and their spectrum limited, indicating scope for improvement. This study identifies a gap evidently created by the mismatch between what we teach and what students actually practice, thus indicating a need to modulate our teaching taking into consideration these practices and lacunae, if we have to effectively convey the risk involved.

\section{Funding: No funding sources Conflict of interest: None declared \\ Ethical approval: The study was approved by the Institutional Ethics Committee}

\section{REFERENCES}

1. Abay SM, Amelo W. Assessment of self-medication practices among medical, pharmacy, and health science students in Gondhar University, Ethiopia. J Young Pharm. 2010;2:306-10.

2. Shankar PR, Partha P, Shenoy N. Self-medication and non-doctor prescription practices in Pokhara valley, Western Nepal: a questionnaire-based study. BMC Family Pract. 2002;3:17. Accessed on 2015 Dec 04

3. Verma RK, Mohan L, Pandey M. Evaluation of selfmedication among professional students in North 
India: proper statutory drug control must be implemented. Asian J Pharm Clin Res. 2010;3:60-4.

4. Lam CLK, Tse MHW, Munro C. A Study on the practice of self-medication in Hong Kong. Hong Kong Pract. 1989;11:272-86.

5. World Health Organization: The role of the pharmacist in self-care and self-medication. Report of the $4^{\text {th }}$ WHO consultative group on the role of the pharmacist. The Hague, 1998. Available from http://apps.who.int/medicinedocs/pdf/whozip32e/wh ozip32e.pdf. Accessed on 2015 Dec 04.

6. James H, Handu SS, Al Khaja KA, Otoom S, Sequeria RP. Evaluation of the knowledge, attitude, and practice of self-medication among first-year medical students. Med Princ Pract. 2006;15:270-5.

7. Nattala P, Murthy P, Kandavel T, Cottler LB. Nonmedical use of prescription drugs in Bangalore, India. Indian J Pub Health. 2015;59:87-94.

8. Pandya RN, Jhaveri KS, Vyas FI, Patel VJ. Prevalence, pattern and perceptions of selfmedication in medical students. Int $\mathrm{J}$ Basic Clin Pharmacol. 2013;2:275-80.

9. Asseray N, Ballereau F, Trombert-Paviot B, Bouget J, Foucher N, Renaud B et al. Frequency and severity of adverse drug reactions due to selfmedication: a cross-sectional multicenter survey in emergency departments. Drug Saf. 2013;36:115968.

10. Sontakke SD, Bajait CS, Pimpalkhute SA, Jaiswal KM, Jaiswal SR. Comparative study of evaluation of self-medication practices in first and third year medical students. Int J Biol Med Res. 2011;2:561-4.

11. Aljinocic-Vucic V, Trkulja V, Lackovic Z. Content of home pharmacies and self-medication practices in households of pharmacy and medical students in Zagreb, Croatia: findings in 2001 with a reference to 1977. Croat Mel J. 2005;46:74-80.

12. Montgomery AJ, Bradley C, Rochfort A, Panagopoulou E. A review of self-medication in physicians and medical students. Occup Med (Lond). 2011;61:497. Available from http://occmed.oxfordjournals.org/content/61/7/490.f ull.pdf. Accessed on 2015 Dec 07.

13. Mehta U. Pharmacovigilance: the devastating consequences of not thinking about adverse drug reactions. Contin Med Educ. 2011;29:247-51.

14. Hem E, Stokke G, Tyssen R, Gronvold NT, Vaglum $\mathrm{P}$, Ekeberg O. Self-prescribing among young Norwegian doctors: a nine-year follow-up study of a nationwide sample. BMC Medicine. 2005,3:16. http://www.biomedcentral.com/1741-7015/3/16. Accessed on 2015 Dec 07.

15. Banerjee I, Bhadury T. Self-medication practice among undergraduate medical students in a tertiary care medical college, West Bengal. J Postgrad Med. 2012;58:127-31.
16. Lukovic JA, Miletic V, Pekmezovic T, Trajkovic G, Ratkovic N, Aleksic D, et al. Self-medication practices and risk factors for self-medication among medical students in Belgrade, Serbia. PloS one 2014;9:e114644.

17. Kumar N, Kanchan T, Unnikrishnan, Rekha $\mathrm{T}$, Mithra P, Kulkarni V et al. Perceptions and practices of self-medication among medical students in coastal South India. PLoS One. 2013;8:e72247.

18. Bala R, Singh H, Kaur K, P Girish, Kohli K. Knowledge and attitude towards antimicrobial selfmedication usage: a cross sectional study among medical and nursing students. Int $\mathbf{J}$ Basic Clin Pharmacol. 2013;2:428-32.

19. Abasaeed A, Vlcek J, Abuelkhair M, Kubena A. Self-medication with antibiotics by the community of Abu Dhabi Emirate, United Arab Emirates. J Infect Dev Ctries. 2009;3:491-7.

20. Nalini GK. Self-Medication among Allopathic medical Doctors in Karnataka, India. BJMP. 2010;3:325. Accessed on 2015 Dec 07.

21. Jaiswal S, Keche YN, Yegnanarayan R, Gajendra G, Chandanwale K, Lanke V et al. Pattern selfmedication use of analgesics in Pune, Maharashtra, India. Int J Res Med Sci. 2014;2:1092-6.

22. BhallaV, Bajaj UK. Abuse and misuse potential of commonly used Non-steroidal anti-inflammatory drugs (NSAIDs) in Indian scenario, A pharmacovigilance model study. Asian J Pharm Tech Inn. 2014;02.

23. Mehta RK, Sharma S. Knowledge, attitude and practice of self-medication among medical students. IOSR J Nurs Health Sci. 2015;4:89-96.

24. Badiger S, Kundapur R, Jain A, Kumar A, Patanashetty S, Thakolkaran N et al. Self-medication patterns among medical students in South India. AMJ. 2012;5:217-20.

25. Phalke VD, Phalke DB, Durgawale PM. Selfmedication practices in rural Maharashtra. Indian $\mathbf{J}$ Comm Med. 2006;31:34-5.

26. Roberts LW, Hardee JT, Franchini G, Stidley CA, Siegler M. Medical students as patients: a pilot study of their health care needs, practices, and concerns. Acad Med. 1996;71:1225-32.

Cite this article as: Burute SR, Burute RB, Murthy MB, Karande VB, Pore SM, Ramanand SJ.

Awareness of adverse drug reactions in third M.B.B.S students practicing self-medication. Int J Basic Clin Pharmacol 2016;5:196-201. 